\title{
Cutaneous angiosarcoma with lymphoedema: the Stewart-Treves syndrome
}

\author{
Amrita Randhawa, ${ }^{1}$ Maxine Paul, ${ }^{2}$ Steven Lo, ${ }^{3}$ Grant Wylie ${ }^{1}$
}

'Dermatology Department, Queen Elizabeth University Hospital, Glasgow, UK ${ }^{2}$ Pathology Department, Queen Elizabeth University Hospital, Glasgow, UK

${ }^{3}$ Plastic Surgery and Burns Unit, Glasgow Royal Infirmary, Glasgow, UK

\section{Correspondence to} Dr Amrita Randhawa, arandhawa@nhs.net

Accepted 22 January 2019

\section{DESCRIPTION}

A 63-year-old woman presents to the medical receiving unit with a 2-month history of violaceous haemorrhagic nodules on her right lower leg on the background of 10-year history of chronic lymphoedema (figure 1). She had a complex medical history including previous deep venous thrombosis (DVT) of the right leg, atrial fibrillation, hypertension, chronic kidney disease, ischaemic heart disease, non-alcohol related fatty liver disease and a progressive neurodegenerative disorder. The worsening spasticity in her lower legs ultimately reduced her mobility and she was subsequently a wheelchair user. The DVT, recurrent cellulitis and immobility/ dependency led to the development of chronic lymphoedema.

A skin biopsy confirmed cutaneous angiosarcoma (figures 2 and 3). Staging CT of the chest, abdomen and pelvis excluded metastatic disease. An MRI scan did not identify any discrete enhancing lesions in the subcutaneous tissues of the right leg. She subsequently had a right transfemoral amputation under the care of the sarcoma specialists following discussion at the National Sarcoma multidisciplinary team meeting. Histology confirmed that clear margins were achieved. She has since recovered without any significant complications and is under the care of the surgical and oncology teams for monitoring for disease recurrence or metastatic disease every 3 months. Adjuvant therapy such as chemotherapy was not warranted with clear surgical margins and in the absence of metastases.

Angiosarcoma is a malignant neoplasm of endothelium that can rarely occur in the context of chronic lymphoedema, known as Stewart-Treves syndrome. This entity, first described in 1948, has

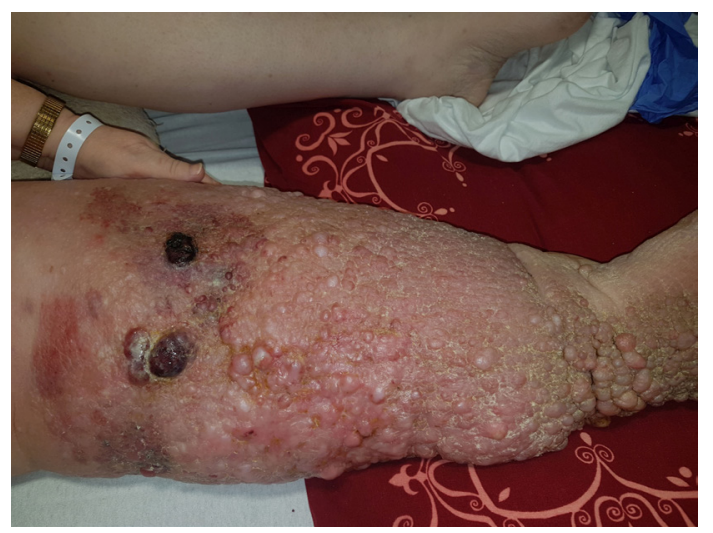

Figure 1 Violaceous nodules on the shin with evidence of skin changes consistent with chronic lymphoedema of the right lower leg.

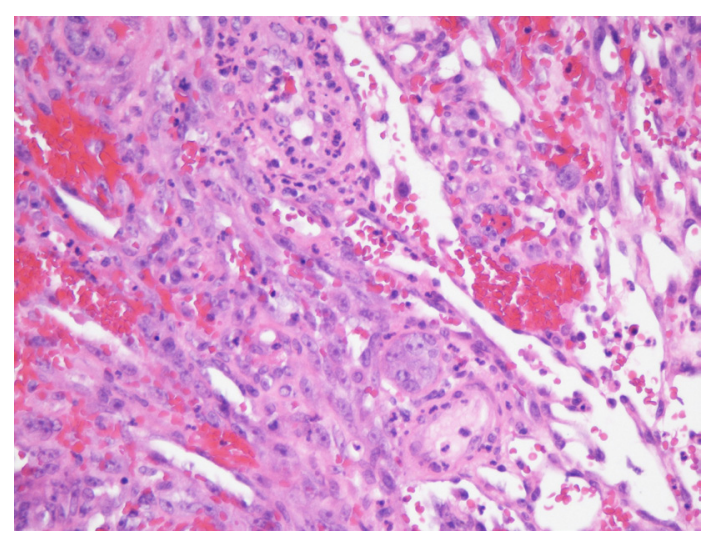

Figure 2 Microscopy showed a high-grade malignant spindle cell tumour with vascular channel formation and red cell extravasation.

historically been associated with post-mastectomy and axillary node dissection following breast cancer diagnosis and therefore usually presents in the upper limbs. It can also be broadly applied to tumours occurring in the lower extremities in patients with primary or secondary chronic lymphoedema. The duration of the lymphoedema prior to appearance of the tumour can range anywhere between 1 and 26 years. ${ }^{1}$ The pathophysiology is still unknown and it is postulated that lymphostasis induces local immunodeficiency and poor immunosurveillance which subsequently promotes vascular oncogenesis. ${ }^{2}$

Stewart-Treves syndrome initially presents with subcutaneous violaceous nodules or eschars which can then progress and coalesce to form indurated plaques with evidence of pitting oedema.

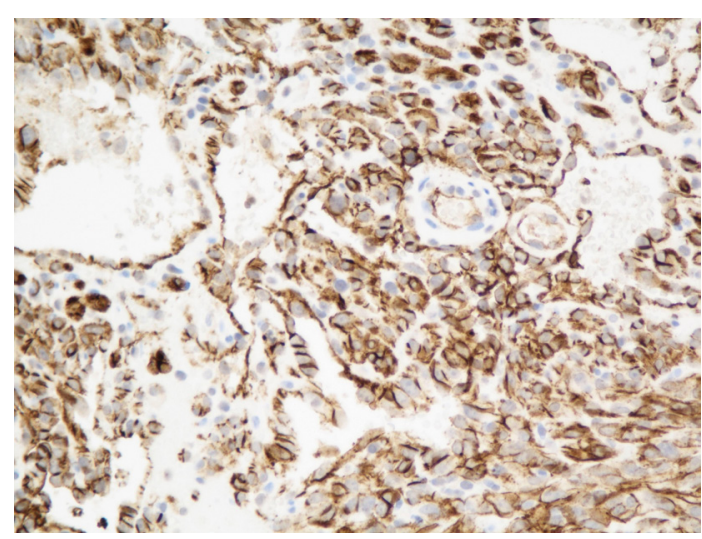

Figure 3 The tumour cells were positive with the immuno-histochemical marker CD31, confirming angiosarcoma. 
Histopathological and immuno-histochemical studies are essential for diagnosis. There is no consensus on the optimal management of angiosarcoma in Stewart-Treves syndrome, but some major sarcoma centres advocate a radical amputation involving forequarter or hindquarter amputation. ${ }^{3}$ Chemotherapy with paclitaxel has been used in a palliative setting in patients with inoperable disease.

This tumour is highly aggressive and prone to metastasis. The overall prognosis is poor with a median survival of 2.5 years. $^{3}$ Therefore, it is important for clinicians to recognise this rare

\section{Learning points}

- Cutaneous angiosarcoma is a malignant vascular neoplasm for which there are three main variants: idiopathic, postradiation and in chronic lymphoedema of the upper limb typically post-mastectomy (Stewart-Treves syndrome).

- Stewart-Treves syndrome presents as bruise-like patches/ plaques, violaceous nodules or ulcerating lesions on the background of lymphoedema. Skin biopsy is imperative to confirm diagnosis.

- The prognosis is poor and therefore early recognition is essential to prevent delay in diagnosis and management. complication of chronic lymphoedema in order to expedite appropriate investigations and treatment. A multidisciplinary approach is vital in the care of these patients. In summary, we present a case of a 63-year-old woman with Stewart-Treves syndrome, a rare cutaneous angiosarcoma on the background of chronic lymphoedema.

Contributors All authors were involved with the patient's care, contributed to the writing of this article and approved the submitted article. AR was responsible for acquisition of clinical data, literature review, conception and article writing. MP $\mathrm{SL}$ and GW revised it critically for important intellectual content and all authors approved the final version/submitted article.

Funding The authors have not declared a specific grant for this research from any funding agency in the public, commercial or not-for-profit sectors.

Competing interests None declared.

Patient consent for publication Obtained.

Provenance and peer review Not commissioned; externally peer reviewed.

\section{REFERENCES}

1 Berebichez-Fridman R, Deutsch YE, Joyal TM, et al. Stewart-Treves syndrome: a case report and review of the literature. Case Rep Oncol 2016:9:205-11.

2 Lee R, Saardi KM, Schwartz RA. Lymphedema-related angiogenic tumors and other malignancies. Clin Dermatol 2014;32:616-20.

3 Roy P, Clark MA, Thomas JM. Stewart-Treves syndrome--treatment and outcome in six patients from a single centre. Eur J Surg Oncol 2004;30:982-6.

Copyright 2019 BMJ Publishing Group. All rights reserved. For permission to reuse any of this content visit https://www.bmj.com/company/products-services/rights-and-licensing/permissions/

BMJ Case Report Fellows may re-use this article for personal use and teaching without any further permission.

Become a Fellow of BMJ Case Reports today and you can:

- Submit as many cases as you like

- Enjoy fast sympathetic peer review and rapid publication of accepted articles

- Access all the published articles

Re-use any of the published material for personal use and teaching without further permission

For information on Institutional Fellowships contact consortiasales@bmjgroup.com

Visit casereports.bmj.com for more articles like this and to become a Fellow 